\title{
Editorial: Common threads in a rich tapestry
}

\section{Heather Joshi}

This is the first issue of Longitudinal and Life Course Studies under its new editorial crew. The transition continues to be gradual. Most of the items we are publishing this time were initiated while John Bynner was still at the helm and many of them were seen through by the outgoing section editors. We continue to benefit from the expertise of Cara Randall as journal manager. The outcome of these joint efforts does not therefore represent any dramatic departure from the journal's course. We maintain the breadth of content and direction of travel in providing a multi-disciplinary, international forum for research on longitudinal data and studies of the life course. These are times when the scientific uses of longitudinal data are proliferating. The technology for creating longitudinal data sets and the methodology for handling and analysing them continue to develop. These are also times when two ambitious large scale cohort studies, in US and UK (the National Children' Study and Life Study), have been abandoned, and when, under fiscal austerity, the costs of data collection are more than ever under scrutiny. The UK's portfolio of investment in longitudinal resources is under an official review from international peers. The future of such investments in other countries is also far from assured. The contributions to this issue of the journal provide evidence of what can be done with some of the existing the data resources, and how longitudinal evidence might be developed in the future.

The first paper in the issue, 'Duration, timing and order: How housing histories relate to later life wellbeing' is by Bram Vanhoutte, Morten Wahrendorf and James Nazroo. They take their evidence, from the English Longitudinal Survey of Ageing, on people over 50 and use several approaches to summarising the history data, and to assessing wellbeing. The paper is novel in its focus on housing as a marker of material progress through life, in its handling of data on sequences, and that it draws on retrospective data. The retrospective approach permits some glimpses of life histories involving international immigration or spells not living in private households which tend to be missed in prospective surveys of private households. All three aspects of wellbeing - affective, cognitive and eudemonic - were lower for those spending adult life as a tenant, particularly if they were downwardly mobile from an owned home in childhood, compared to those whose pathways through housing histories had more sustained owner occupation. The highest wellbeing scores were associated with those who had been living abroad as children. The findings also illustrate the importance for life course studies of allowing for historical contexts. The association of owner occupation and social advantage may have been particularly strong in late Twentieth Century England.

The second paper, 'Moving up, feeling down: socioemotional health during the transition into college' by Julie Olson takes us to the US, and a life stage which normally represents positive progress, but has its own perils. The Add Health survey provides evidence on the mental health of young people over six years as they move into college from high school. It uses the same Depression Scale, (CES-D) as used by Vanhoutte and colleagues for the affective wellbeing of older English people. Here it is used to construct contrasting trajectories of depressive symptoms, across three waves of data. These are related to information about the competitiveness in their educational environments and the curriculum studied. The hypothesis that those with a strong deterioration in their mental health would be those encountering more competitive regimes in college than school was not borne out. However those majoring in maths and science subjects seemed more successful in sustaining good mental health.

The third paper 'Linkable administrative data: Increasing the value of existing information', by Leslie Roos, describes the potential of linked administrative datasets to provide a rich information resource for research. This is illustrated in the de-identified population data repository held by the government of Manitoba in Canada. She emphasises the institutional environment which ensures co-operation between data providers, and the 'smiling persistence' needed to bring additional sources in. This is not always replicated in other settings, even most other Canadian provinces. There are some kinds of data which one cannot 
expect record linkage to provide, which suggests that the way forward may be to supplement survey data with administrative records, rather than to supplant them. This entails surveys collecting permission to link administrative data, often hitherto under-used.

| Our fourth contribution is one of the first journal publications to appear that draws lessons from the experience of the Life Study, which would have been the fifth British birth cohort study, until it was closed down in 2015. 'Innovations in the design and analysis of cohort studies: integrating area-based and national samples' is research note from

Harvey Goldstein, Francesco Sera, Peter Elias and Carol Dezateux, about one particular aspect of Life Study design: the combination of local hospitalbased studies with a national probability survey. The authors describe how weighting was proposed, and could be used in studies elsewhere with a similar dual design. It is expected this journal will be publishing more about the Life Study in due course.

The next contribution, 'Is there a wage penalty associated with degree of indecision in career aspirations?' is a research note by Ricardo Sabates, Leslie Gutman and Ingrid Schoon. They use data linking 16 year olds in the British Cohort of 1970 with their attainment in the labour market in midlife. The interest is in relating the precision of occupational aspirations of teenagers with hourly pay at age 34. A degree of imprecision at 16 seemed not to matter for pay at 34 . Those with complete uncertainty had lower pay, but this largely reflected in failure to acquire educational qualifications. Though neither this nor Olson's paper explores this question, taken together these contributions suggest, as a topic for further research, the role mental ill-health in less successful transitions to adulthood. Furthermore, they both illustrate uses of prospective data, on aspirations, expectations or depressive symptoms the sort of information that cannot be assembled from administrative sources.

The final paper,- 'Journeys Home: tracking the most vulnerable' by Rosanna Scutella, Yi-Ping Tseng and Mark Wooden - is a study profile from Australia. It provides a novel example of a combination of administrative and survey data collection to reach a little-studied group - the homeless and those at risk of homelessness. Such people tend to be missed by conventional household surveys, but are clearly of interest to policy makers as well as social scientists. The exercise was made possible by the collaboration between the researchers and the income support authorities. It proved possible to select and follow a sample of vulnerable individuals for 6 waves over 3 years from 2011. The study profile gives references to published research results and details of the possibilities for secondary analysis. Typical of such data collaborations elsewhere, there are some restrictions on the secondary use of some administrative variables.

The new editorial team hope that readers will enjoy this selection, not only finding connections across the pieces but inspiration to keep submitting more material. 